OPEN ACCESS

Edited by:

Zhenyu Li,

Deakin University, Australia

Reviewed by:

Ming-Guo Ma

Beijing Forestry University, China Hua Wang,

Beihang University, China

Wei Wang,

Harbin Institute of Technology, China

*Correspondence:

Wei-Gen Chen

weigench@cqu.edu.cn

Specialty section: This article was submitted to Nanoscience,

a section of the journa

Frontiers in Chemistry

Received: 12 May 2018 Accepted: 18 September 2018

Published: 11 October 2018

Citation:

Zhang $H$, Chen W-G, Li Y-Q, Jin L-F, Cui F and Song Z-H (2018) 3D

Flower-Like NiO Hierarchical

Structures Assembled With Size-Controllable 1D Blocking Units: Gas Sensing Performances Towards Acetylene. Front. Chem. 6:472. doi: 10.3389/fchem.2018.00472

\section{D Flower-Like NiO Hierarchical Structures Assembled With Size-Controllable 1D Blocking Units: Gas Sensing Performances Towards Acetylene}

\author{
He Zhang ${ }^{1}$, Wei-Gen Chen ${ }^{1 *}$, Yan-Qiong Li $^{2}$, Ling-Feng Jin ${ }^{1}$, Fang Cui ${ }^{1}$ and Zi-Hao Song ${ }^{1}$ \\ 1 State Key Laboratory of Power Transmission Equipment \& System Security and New Technology, School of Electrical \\ Engineering, Chongqing University, Chongqing, China, ${ }^{2}$ School of Electronic and Electrical Engineering, Chongqing \\ University of Arts and Sciences, Chongqing, China
}

Acetylene gas $\left(\mathrm{C}_{2} \mathrm{H}_{2}\right)$ is one of the main arc discharge characteristic gases dissolved in power transformer oil. It is of great potential to monitor the fault gas on-line by applying gas sensor technology. In this paper, gas sensors based on nanorods and nanoneedles assembled hierarchical $\mathrm{NiO}$ structures have been prepared. Herein, we focus on investigate the relationship between the sizes of the assembling blocking units and gas sensing properties. It can be found that the addition of CTAB/EG plays a vital role in controlling the sizes of blocking unit and assembly manner of 3D hierarchical structures. A comparison study reveals that an enhanced gas sensing performance toward $\mathrm{C}_{2} \mathrm{H}_{2}$ for the sensor based on nanoneedle-assembled $\mathrm{NiO}$ flowers occurs over that of nanorod-assembled $\mathrm{NiO}$. This enhancement could be ascribed to the larger specific area of needle-flower, which provides more adsorption and desorption sites for chemical reaction as well as effective diffusion channels for $\mathrm{C}_{2} \mathrm{H}_{2}$. Besides, a method of calculating the specific surface area without BET testing was presented to verify the results of gas sensing measurement. The possible growth mechanism and gas sensing mechanism were discussed. Such a synthesis way may open up an avenue to tailor the morphologies and control the sizes of blocking units of some other metal oxides and enhance their gas sensing performances.

Keywords: NiO, hierarchical structures, blocking units, sensor, gas sensing performances

\section{INTRODUCTION}

As we all know, the stable and reliable operation of power transformers is particularly important for the safety and stability of power system. When the oil-immersed power transformers work for a long time, the insulating oil, and paper will gradually deteriorate and produce various trace characteristic gases, which actually dissolve in transformer insulation oil (Singh and Bandyopadhyay, 2010). When the power transformer has the spark of oil or arc discharge fault, it will generate the fault characteristic gas with acetylene gas $\left(\mathrm{C}_{2} \mathrm{H}_{2}\right)$ as the main component. It is of great potential to monitor the fault gas on-line by applying gas sensor technology. The monitoring 
of $\mathrm{C}_{2} \mathrm{H}_{2}$ gas content can predict the internal latent failure of the transformer (Chen et al., 2013; Jin et al., 2017). So, $\mathrm{C}_{2} \mathrm{H}_{2}$ gas is selected as the target gas in this paper.

A common method for detecting $\mathrm{C}_{2} \mathrm{H}_{2}$ gas dissolved in transformer oil is metal oxide semiconductor (MOS) based gas sensor (Zhu and Zeng, 2017). Among various MOS sensing materials, nickel oxide $(\mathrm{NiO})$ as a wide band gap $(\mathrm{Eg}=3.6-$ $4.0 \mathrm{ev}$ ) p-type semiconductor has taken a dominated position due to its outstanding physical and chemical properties. Recently, $\mathrm{NiO}$ has been extensively applied in multifarious application fields such as electrode materials (Zhang et al., 2004), solar cells (Nakasa et al., 2005), catalysts (Kaminski et al., 2018), and gas sensors (Cao et al., 2015a; Yu et al., 2017).

It's believed that one-dimensional (1D) nanostructures with large surface to volume have great potential to improve the sensing properties. However, there are some shortcomings for 1D structure, i.e., inevitable serious stacking configuration and thermal/ chemical instability. Given this, the sensing materials can be designed into three-dimensional (3D) hierarchical structure assembled by $1 \mathrm{D}$ blocking units, which not only prevents the $1 \mathrm{D}$ blocking units from serious stacking but also inherits the merits of 1D nanomaterials (Duo et al., 2016; Zhu et al., 2018). The ability to control the assembly configuration, the morphology and size of building units in hierarchical architectures is of utmost importance for the realization of multifunctional nanodevices (Kim and Yong, 2011). Recently, assembly of $1 \mathrm{D}$ blocking units into hierarchical structures has been a hot topic in the research. But there are few explorations about the synthesis of hierarchical structures with size-controllable blocking units and studying the influence of the size of the assembling units on gas sensing performances.

In this paper, nanorods, and nanoneedles assembled $3 \mathrm{D}$ flower-like $\mathrm{NiO}$ hierarchical structures were successfully synthesized via hydrothermal synthesis. Herein, we focus on investigate the relationship between the sizes of the assembling blocking units and gas sensing properties. It can be found that the addition of CTAB/EG plays a vital role in controlling the sizes of blocking unit and assembly manner of 3D hierarchical structures. A comparison study reveals that an enhanced gas sensing performance toward $\mathrm{C}_{2} \mathrm{H}_{2}$ for the sensor based on nanoneedle-assembled $\mathrm{NiO}$ flowers occurs over that of nanorodassembled $\mathrm{NiO}$. In order to shed light on this phenomenon, a method of calculating the specific surface area without BET testing was presented to verify the results of gas sensing measurement. Based on our experimental results, the possible formation mechanism of two kinds of $\mathrm{NiO}$ nanoflowers is primarily discussed. It's expected that this study can promote the development of gas sensing materials via lower dimensional assembly.

\section{EXPERIMENTAL}

\section{Synthesis of the Nanorods-Assembled Hierarchical NiO Nanoflowers}

In a typical experiment of nanorods assembled $\mathrm{NiO}$ nanoflowers, $0.4 \mathrm{~g}$ of $\mathrm{Ni}\left(\mathrm{NO}_{3}\right)_{2} \cdot 6 \mathrm{H}_{2} \mathrm{O}$ was added to $40 \mathrm{ml}$ of distilled water under vigorous stirring for $10 \mathrm{~min} .0 .18 \mathrm{~g}$ of cetyltrimethyl ammonium bromide (CTAB) was introduced into the above solution. Then, under continuous magnetic stirring, ammonia $\left(\mathrm{NH}_{3} \cdot \mathrm{H}_{2} \mathrm{O}, 25 \%\right)$ was dripped into the mixed solution to obtain the $\mathrm{pH}=9$. After thorough mixing, the resulting mixture was transferred to a $50 \mathrm{ml}$ autoclave and maintained overnight at $180^{\circ} \mathrm{C}$. After cooling naturally, the precipitates were washed sequentially and dried in air at $60^{\circ} \mathrm{C}$. Finally, the powder was calcined at $500^{\circ} \mathrm{C}$ for $2 \mathrm{~h}$. The sample was labeled as rod-flower.

\section{Synthesis of the Nanoneedles-Assembled Hierarchical NiO Nanoflowers}

Typically, $0.4 \mathrm{~g}$ of $\mathrm{NiCl}_{2} \cdot 6 \mathrm{H}_{2} \mathrm{O}$ and $0.08 \mathrm{~g}$ of $\mathrm{Na}_{2} \mathrm{C}_{2} \mathrm{O}_{4}$ were poured into $15 \mathrm{ml}$ of distilled water. Then $25 \mathrm{ml}$ ethylene glycol (EG) was added into the solution with sequentially stirring. The mixed solution was loaded into a $50 \mathrm{ml}$ autoclave and heated to $160^{\circ} \mathrm{C}$ for $12 \mathrm{~h}$. The subsequent process including centrifugation, washing, drying and calcining are the same as the above. The sample after annealing was designated as needle-flower.

\section{Characterization}

Crystal structure of as-prepared samples was examined through X-ray diffraction (XRD, D/Max-1200X, Rigaku). The surface morphologies and nanostructures of the samples were inspected by scanning electronic microscopy (SEM, JEM-6700F) and transmission electron microscopy (TEM, JEM-1200EX).

The detailed process about the fabrication of planar gas sensor and gas-sensing test is as follows Jin et al. (2017). Firstly, the appropriate amount of as-prepared $\mathrm{NiO}$ powders was fully ground and mixed with diethanolamine and ethanol to form a slurry suspension. The pastes were evenly coated onto the electrodes of sensor's substrate. Then, the sensor was placed in aging platform and maintained at $120^{\circ} \mathrm{C}$ for $100 \mathrm{~h}$ to improve the stability of the sensor. Gas sensing properties toward $\mathrm{C}_{2} \mathrm{H}_{2}$ were measured using a CGS-1TP (Chemical Gas Sensor1 Temperature Pressure) intelligent gas sensing analysis system. The sensor was placed on the heating table of the gas chamber and two probes were adjusted to ensure good electrical signals of the sensing materials. Then, the working temperature was set and air was delivered into the chamber at a constant flow rate. When the resistance of the sensor was stable in the air, it's denoted as $\mathrm{Ra}$. Then, a certain amount of target gas was injected into the chamber through the injection hole. The change of resistance curve in the software was observed until the resistance value was stable again, denoted as Rg. The target gas flow was vented and the sensor was exposed to air again. The concentration of target gas $\left(\mathrm{C}_{2} \mathrm{H}_{2}\right)$ was controlled by the mass flow controllers (MFC) with the following equation (Equation 1):

$$
\begin{aligned}
& \text { Gas concentration }(\mathrm{ppm}) \\
& =\frac{\text { Flow rate }(\text { target gas }) \times \text { Gas cylinder }(\text { target gas })}{\text { Flow rate }(\text { target gas })+\text { Flow rate }(\text { air })}
\end{aligned}
$$

The response (S) of the sensor was defined as the ratio of $\mathrm{Rg}$ to $\mathrm{Ra}$. And the response (recovery) time was regarded as the time required reach $90 \%$ of the total resistance change. 


\section{RESULTS AND DISCUSSION}

\section{Morphology and Structure}

Figure 1A shows the XRD patterns of the obtained samples. The identified peaks in two curves can be well matched with the cubic crystalline structure of $\mathrm{NiO}$ (JCPDS Card no. 04-0835) without observable impurity peaks, demonstrating that high purity of $\mathrm{NiO}$. Morphologies and structural features of the samples are characterized by SEM and TEM, as shown in Figures 1B-E. From Figure 1B, the $\mathrm{NiO}$ hierarchical nanoflowers are assembled from a bunch of well-defined nanorods. The roots of these nanorods come together while the tips are detached. Figure 1C illustrates that each individual nanorod from the flower shared the same geometric center. The average diameter of these nanorods is $\sim 900 \mathrm{~nm}$ and the length is $\sim 6 \mu \mathrm{m}$. Additionally, some rods are scattered around flower-like structures. As observed in the inset of Figure 1C, the size of nanorods was similar to what we had observed in SEM images. In Figure 1D, the nanoneedles are assembled into homogeneously distributed flower-like structures (AlHadeethi et al., 2017). The magnified SEM image in Figure 1E displays the nanoneedles are thicker at roots with sharper emanative ends. Each needle is $\sim 2.5 \mathrm{um}$ in length and $\sim 80 \mathrm{~nm}$ in diameter at the middle, which is in consistence with the observation in TEM image (the inset of Figure 1E).

\section{Formation Mechanism}

Based on the above observations, we proposed a possible formation mechanism for the morphologies evolution of the nanorod-assembled $\mathrm{NiO}$ nanoflowers, as shown in Figure 2A. Firstly, ammonia aqueous acts as an alkaline reagent to release $\mathrm{OH}^{-}$ions. CTAB is a surfactant with a hydrophobic part (Li Y.
Q. et al., 2015; Liu et al., 2017). When the $\mathrm{Ni}(\mathrm{OH})_{2}$ comes across $\mathrm{CTAB}, \mathrm{Ni}(\mathrm{OH})_{2}$ will be preferably absorbed on the $\mathrm{CTA}^{+}$heads. Subsequently, the grown $\mathrm{Ni}(\mathrm{OH})_{2}$ nanoparticles are connected with each other by orientation attachment to form many nanorods. It's proposed that CTAB seemingly acts as an adhesive to gather the nanorods together (Li T. M. et al., 2015; Miao et al., 2017). Finally, the nanorods self-assemble into the ultimate flower-like architectures driven by the minimum surface energy theory.

For the formation of the nanoneedle-assembled hierarchical $\mathrm{NiO}$ nanoflowers (Figure 2B), firstly, $\mathrm{Ni}^{2+}$ and $\mathrm{C}_{2} \mathrm{O}_{4}^{2-}$ can be illustrated as a $\mathrm{NiC}_{2} \mathrm{O}_{4} \cdot 2 \mathrm{H}_{2} \mathrm{O}$ polymer type ribbon owing to the complexation of $\mathrm{Ni}^{+}$and $\mathrm{C}_{2} \mathrm{O}_{4}^{2-}$. EG is a surfactant with symmetrical structures and functional group- $\mathrm{OH}$, which serves as a ligand to $\mathrm{Ni}$ and blocked the crystal surface paralleled to $[0,1,1]$ direction (Cao et al., 2015b). And then the above microstructures are connected with each other along $[0,1,1]$ direction fabricate the needle-like structures. With the reaction time goes by, $\mathrm{NiC}_{2} \mathrm{O}_{4} \cdot 2 \mathrm{H}_{2} \mathrm{O}$ nanoneedles aggregate with each other to assemble into hierarchical needle-flower. Finally, NiO nanoflowers are obtained by thermal calcination.

\section{Gas Sensing Properties}

To further study the connection between the size of the assembling units and gas sensing performances, we conduct gas sensing experiments. Firstly, we investigate gas response curves with temperature changing toward $200 \mathrm{ppm} \mathrm{C}_{2} \mathrm{H}_{2}$. In Figure $2 \mathrm{C}$, there is a volcano-shaped trend for the changes in gas response of both kinds of nanoflowers. Apparently, the gas response of the needle-flower $\mathrm{NiO}$ is higher than that of rod-flower. The responses at peaks are 15.76 and 25.71 at $300^{\circ} \mathrm{C}$, respectively (Long et al., 2018; Zhang et al., 2018). Herein, we determine the


FIGURE 1 | (A) XRD patterns of the obtained samples. (B,C) SEM images of the rod-flower NiO and TEM image in the inset of (C). (D,E) SEM images of the needle-flower NiO and TEM image in the inset of (E). 
A

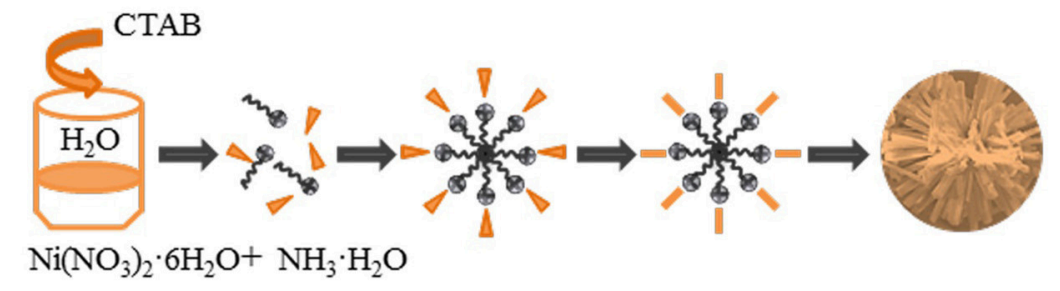

- - $\mathrm{Ni}(\mathrm{OH})_{2} \quad$ mu- $\mathrm{CTA}^{+}$

NiCl

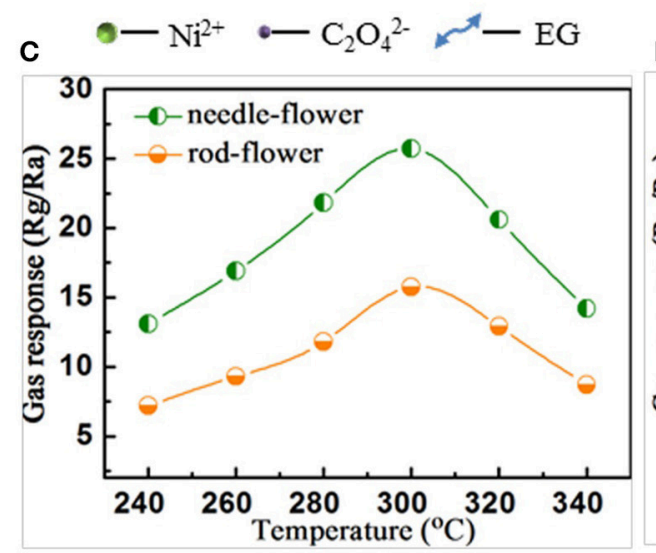

D

E

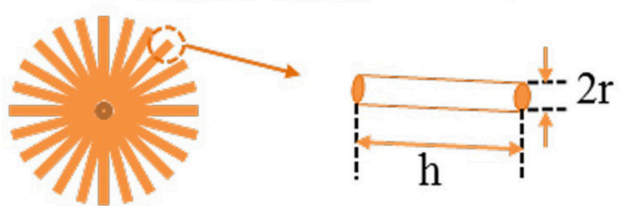

FIGURE 2 | (A,B) Schematic of the formation process. (C) Gas response as the function of operating temperature under $\mathrm{C}_{2} \mathrm{H}_{2}$ concentration of 200 ppm. (D) The response and recovery characteristics of rod-flower and needle-flower $\mathrm{NiO}$ under $\mathrm{C}_{2} \mathrm{H}_{2}$ concentration of $200 \mathrm{ppm}$ at $300^{\circ} \mathrm{C}$. (E) A simplified model to calculate the surface area of hierarchical $\mathrm{NiO}$ nanoflowers.

optimum working temperature to be $300^{\circ} \mathrm{C}$ for the later testing. Figure 2D demonstrates the response and recovery characteristic of hierarchical $\mathrm{NiO}$ nanoflowers toward $200 \mathrm{ppm} \mathrm{C}_{2} \mathrm{H}_{2}$ at $300^{\circ} \mathrm{C}$. Both sensors exhibit excellent gas sensing performances. It's clearly seen that the response of the needle-flower $\mathrm{NiO}$ is higher than that of rod-flower. Besides, the needle-flower $\mathrm{NiO}$ exhibits a shorter response and recovery time (23 and $26 \mathrm{~s}$ ) compared with that of the rod-flower $\mathrm{NiO}$ (34 and $32 \mathrm{~s}$ ). In addition, a comparison about the sensing performances of $\mathrm{NiO}$ sensors in this work and other literature reports is summarized in Table $\mathbf{1 .}$ It is not difficult to find that the needle-flower $\mathrm{NiO}$ based gas sensor in this paper has excellent gas sensing characteristics and has great potential to be a promising candidate for gas-sensitive materials (Lin et al., 2015; Lu et al., 2016; Majhi et al., 2018; San et al., 2018).
Whether the working temperature vs. response or the response and recovery characteristic, sensor based on needleflower $\mathrm{NiO}$ absolutely prevails over that of rod-flower. This may be attributed to the needle-flower's high surface area. In order to verify this hypothesis, we use a simple simplified model to calculate the surface area of the hierarchical $\mathrm{NiO}$ structures (Figure 2E) from associated literature (Lee, 2009; Zhang et al., 2012). We made a slight change according to our data based on the theory. Whether constituent blocking units are nanorods or naononeedles, this proposal has reasonable guiding significance to conduct qualitative analysis. In this modified model, the specific surface area (Equation 2) is

$$
S \cong \frac{\left(\pi r^{2}+2 \pi r h\right) n}{n \pi r^{2} \rho} \sim \frac{1}{\rho}\left(1+\frac{2 h}{r}\right)
$$


TABLE 1 | Comparison of $\mathrm{NiO}$ based gas sensor in this work and those literature reports.

\begin{tabular}{|c|c|c|c|c|}
\hline $\begin{array}{l}\text { Sensing } \\
\text { materials }\end{array}$ & $\begin{array}{l}\text { Target gas } \\
\text { (ppm) }\end{array}$ & $\begin{array}{c}\text { Temperature } \\
\left({ }^{\circ} \mathrm{C}\right)\end{array}$ & Response & References \\
\hline Needle-flower $\mathrm{NiO}$ & $\begin{array}{l}\text { Acetylene } \\
200 \text { ppm }\end{array}$ & 300 & 25.71 & This work \\
\hline Rod-flower $\mathrm{NiO}$ & $\begin{array}{l}\text { Acetylene } \\
200 \text { ppm }\end{array}$ & 300 & 15.76 & This work \\
\hline $\begin{array}{l}\text { Hollow } \mathrm{NiO} / \mathrm{SnO}_{2} \\
\text { heterostructure }\end{array}$ & $\begin{array}{l}\text { Acetylene } \\
100 \text { ppm }\end{array}$ & 206 & 13.8 & Lin et al., 2015 \\
\hline $\begin{array}{l}\text { Porous cactus-like } \\
\mathrm{NiO}\end{array}$ & $\begin{array}{l}\text { Acetone } 100 \\
\text { ppm }\end{array}$ & 260 & 13.51 & Lu et al., 2016 \\
\hline $\begin{array}{l}\mathrm{NiO} / \mathrm{ZnO} \\
\text { heterojunction } \\
\text { microflowers }\end{array}$ & $\begin{array}{l}\text { Formaldehyde } \\
100 \text { ppm }\end{array}$ & 200 & 13.1 & San et al., 2018 \\
\hline $\begin{array}{l}\text { Pristine } \mathrm{NiO} \\
\text { nanoparticles }\end{array}$ & $\begin{array}{l}\text { Ethanol } \\
100 \mathrm{ppm}\end{array}$ & 300 & 1.88 & Majhi et al., 2018 \\
\hline $\begin{array}{l}\text { Core-shell } \\
\mathrm{Au} @ \mathrm{NiO}\end{array}$ & $\begin{array}{l}\text { Ethanol } \\
100 \text { ppm }\end{array}$ & 200 & 2.54 & Majhi et al., 2018 \\
\hline
\end{tabular}

Where $S$ stands for the specific surface area, $r$ is the equivalent radius of $1 \mathrm{D}$ unit, $\mathrm{h}$ is the length of $1 \mathrm{D}$ unit which can be also expressed as the radius of hierarchical structures, $n$ is the number and $\rho$ is the density of $1 D$ unit. To a specific material, $\rho$ can be considered as a constant. So $\mathrm{S}$ is proportional to $\mathrm{h} / \mathrm{r}$. Through the measurement and calculation, the $\mathrm{h} / \mathrm{r}$ value (66.7) of the nanoneedles is $\sim 5$ times that of the nanorods (13.4). So the $\mathrm{S}$ of the needleflower is larger. It can explain why the needle-flower $\mathrm{NiO}$ shows higher gas response and rapid response/recovery behavior. The larger specific area will provide many adsorption and desorption sites for oxygen, leading to the increasement in the conductivity.

\section{Gas Sensing Mechanism}

The sensing mechanism of $\mathrm{NiO}$-based gas sensors involves three serial reactions: adsorption-oxidation-desorption (Zhu et al., 2017). In the case of p-type semiconductor, its carrier is the hole with positive charge. Specifically, when the sensor is in the air, oxygen molecules react with $\mathrm{NiO}$ surface (Equations 3, $4)$. Due to the above reaction, electrons on the $\mathrm{NiO}$ surface combine with $\mathrm{O}_{2}$ to form oxygen negative ions $\left(\mathrm{O}_{2}^{-}, \mathrm{O}^{-}\right.$, and $\left.\mathrm{O}^{2-}\right)$. This process cause the decrease of electrons and the increase of holes to form a hole accumulation layer, resulting in the resistance of the sensor decreases correspondingly. When $\mathrm{NiO}$ surface comes into contact with $\mathrm{C}_{2} \mathrm{H}_{2}$ gas, oxygen ions will oxidize gas molecules into $\mathrm{CO}_{2}$ and $\mathrm{H}_{2} \mathrm{O}$, and releases electrons to recombine with holes (Equations 5, 6), leading to the decrease of carriers in hole accumulation layer and an increase in the resistance (Balamurugan et al., 2014; San et al., 2015).

$$
\begin{aligned}
\mathrm{O}_{2} \text { (gas) } & \rightarrow \mathrm{O}_{2} \text { (ads) } \\
\mathrm{O}_{2}(\text { ads })+\mathrm{ne}^{-} & \rightarrow \mathrm{O}^{\mathrm{n}-}(\text { ads }) \\
\mathrm{C}_{2} \mathrm{H}_{2}(\text { gas }) & \rightarrow \mathrm{C}_{2} \mathrm{H}_{2}(\text { ads }) \\
\mathrm{C}_{2} \mathrm{H}_{2} \text { (ads) }+\mathrm{O}^{\mathrm{n}-}(\text { ads })^{-} & \rightarrow \mathrm{CO}_{2}+\mathrm{H}_{2} \mathrm{O}+\mathrm{ne}^{-}
\end{aligned}
$$

\section{CONCLUSION}

In summary, nanorods and nanoneedles assembled $\mathrm{NiO}$ hierarchical structures have been successfully synthesized via a hydrothermal method and annealing process. Based on the comparative studies, we draw a conclusion that the size (length and diameter) of blocking units has a great influence on gas sensing properties of hierarchical structures. The integral morphologies and sizes of blocking units can be controlled by tuning the additives. Here, CTAB/EG was introduced as a structure-directing agent to regulate the aggregation and assembly. Compared with rod-flower $\mathrm{NiO}$, the needle-flower $\mathrm{NiO}$ based sensor exhibits an enhanced gas sensing performance. This enhancement could be ascribed to the larger specific area of needle-flower, which provides more adsorption and desorption sites for chemical reaction as well as abundant effective diffusion channels for $\mathrm{C}_{2} \mathrm{H}_{2}$. The results hold a novel point in constructing highly efficient gas sensors. The detection capability of gas sensors determines the effectiveness of transformer on-line monitoring. Therefore, optimize the morphology and structure of gas sensitive materials is very meaningful work. Gas sensors with the advantages of miniaturization structure, high sensitivity, and fast response speed have very high practical value in power system security.

\section{AUTHOR CONTRIBUTIONS}

$\mathrm{HZ}$ and $\mathrm{W}-\mathrm{GC}$ conceived and designed the experiments. $\mathrm{HZ}, \mathrm{Y}-\mathrm{QL}$, and L-FJ performed the experiments. FC and Z-HS analyzed the data. HZ wrote the manuscript with input from all authors. All authors read and approved the manuscript.

\section{FUNDING}

This work was supported by the National 111 Project of the Ministry of Education of China (No. B08036), the Plan of Innovation Team Construction from Chongqing Universities (No. CXTDX201601001), and the Scientific Research Fund of Chongqing University of Arts and Sciences (2017RDQ38).

\section{ACKNOWLEDGMENTS}

We thank the State Key Laboratory of Power Transmission Equipment and System Security and New Technology, Chongqing University for supporting this study. 


\section{REFERENCES}

AlHadeethi, Y., Umar, A., Ibrahim, A. A., AlHeniti, S. H., Kumar, R., and Baskoutas, S., et al. (2017). Synthesis, characterization and acetone gas sensing applications of Ag-doped $\mathrm{ZnO}$ nanoneedles. Ceram. Int. 43, 6765-6770. doi: 10.1016/j.ceramint.2017.02.088

Balamurugan, C., Maheswari, A. R., and Lee, D. W. (2014). Structural, optical, and selective ethanol sensing properties of p-type semiconducting $\mathrm{CoNb}_{2} \mathrm{O}_{6}$ nanopowder. Sens. Actuators B Chem. 205, 289-297. doi: 10.1016/j.snb.2014.08.076

Cao, S. K., Zeng, W., Li, T. M., Gong, J., and Zhu, Z. J. (2015a). Hydrothermal synthesis of $\mathrm{NiO}$ nanobelts and the effect of sodium oxalate. Mater. Lett. 156, 25-27. doi: 10.1016/j.matlet.2015.04.149

Cao, S. K., Zeng, W., Long, H. W., Gong, J., Zhu, Z. J., and Chen, L. (2015b). Synthesis and controlled growth of $\mathrm{NiO}$ hierarchical bundle-like nanoflowers with the assistance of ethylene glycol. Mater. Lett. 161, 275-277. doi: 10.1016/j.matlet.2015.08.129

Chen, W. G., Zhou, Q., Gao, T. Y., Su, X. P., and Wan, F. (2013). Pd-doped $\mathrm{SnO}_{2}$ based sensor detecting characteristic fault hydrocarbon gases in transformer oil. J. Nanomater. 2013, 2527-2531. doi: 10.1155/2013/127345

Duo, S. D., Li, Y. Y., Zhang, H., Liu, T. Z., Wu, K., and Li, Z. Q. (2016). A facile salicylic acid assisted hydrothermal synthesis of different flower-like $\mathrm{ZnO}$ hierarchical architectures with optical and concentrationdependent photocatalytic properties. Mater. Character. 114, 185-196. doi: 10.1016/j.matchar.2016.02.021

Jin, L. F., Chen, W. G., Zhang, H., Xiao, G. W., Yu, C. T., and Zhou, Q. (2017). Characterization of reduced graphene oxide (rGO)-loaded $\mathrm{SnO}_{2}$ nanocomposite and applications in $\mathrm{C}_{2} \mathrm{H}_{2}$ gas detection. Appl. Sci. 7, 19-33. doi: 10.3390/app7010019

Kaminski, T., Anis, S. F., Husein, M. M., and Hashaikeh, R. (2018). Hydrocracking of athabasca VR using $\mathrm{NiO}-\mathrm{WO}_{3}$ zeolite-Based catalysts. Energ. Fuel. 32, 2224-2233. doi: 10.1021/acs.energyfuels.7b03754

Kim, J. Y., and Yong, K. J. (2011). Mechanism study of $\mathrm{ZnO}$ nanorodbundle sensors for $\mathrm{H}_{2} \mathrm{~S}$ gas sensing. J. Phys. Chem. C 115, 7218-7224. doi: $10.1021 /$ jp110129f

Lee, J. H. (2009). Gas sensors using hierarchical and hollow oxide nanostructures: overview. Sens. Actuators B Chem. 140, 319-336. doi: 10.1016/j.snb.2009.04.026

Li, T. M., Zeng, W., Zhang, Y. Y., and Hussain, S. (2015). Nanobelt-assembled nest-like $\mathrm{MoO}_{3}$ hierarchical structure: hydrothermal synthesis and gas-sensing properties. Mater. Lett. 160, 476-479. doi: 10.1016/j.matlet.2015.08.031

Li, Y. Q., Liu, T. M., Li, T. M., and Peng, X. H. (2015). Hydrothermal fabrication of controlled morphologies of $\mathrm{MoO}_{3}$ with CTAB: structure and growth. Mater. Lett. 140, 48-50. doi: 10.1016/j.matlet.2014.10.153

Lin, Y., Li, C., Wei, W., Li, Y. J., Wen, S. P., Sun, D. M., et al. (2015). A new type acetylene gas sensor based on hollow heterostructure. RSC Adv. 5, 61521-61527. doi: 10.1039/c5ra10327d

Liu, S. L., Zeng, W., and Chen, T. (2017). Synthesis of hierarchical flower-like $\mathrm{NiO}$ and the influence of surfactant. Phys. E 85, 13-18. doi: 10.1016/j.physe.2016.08.016

Long, H. W., Zeng, W., Wang, H., Qian, M. M., Liang, Y. H., and Wang, Z. (2018). Self-Assembled biomolecular 1D nanostructures for aqueous sodium-Ion battery. Adv. Sci. 5, 1700634-1700637. doi: 10.1002/advs.201 700634

Lu, Y., Ma, Y. H., Ma, S. Y., Jin, W. X., Yan, S. H., Xu, X. L., et al. (2016). Synthesis of cactus-like $\mathrm{NiO}$ nanostructure and their gas-sensing properties. Mater. Lett. 164, 48-51. doi: 10.1016/j.matlet.2015.10.117
Majhi, S. M., Naik, G. K., Lee, H. J., Song, H. G., Lee, C. R., Lee, I. H., et al. (2018). $\mathrm{Au} @ \mathrm{NiO}$ core-shell nanoparticles as a p-type gas sensor: novel synthesis, characterization, and their gas sensing properties with sensing mechanism. Sens. Actuators B Chem. 268, 223-231. doi: 10.1016/j.snb.2018.04.119

Miao, R. Y., Zeng, W., and Gao, Q. I. (2017). Hydrothermal synthesis of novel NiO nanoflowers assisted with CTAB and SDS respectively and their gas-sensing properties. Mater. Lett. 186, 175-177. doi: 10.1016/j.matlet.2016.09.127

Nakasa, A., Usami, H., Sumikura, S., Hasegawa, S., Koyama, T., and Suzuki, E. (2005). A high voltage dye-sensitized solar cell using a nanoporous $\mathrm{NiO}$ photocathode. Chem. Lett. 34, 500-501. doi: 10.1246/cl.2005.500

San, X. G., Li, M., Liu, D. Y., Wang, G. S., Shen, Y. B., Meng, D., et al (2018). A facile one-step hydrothermal synthesis of $\mathrm{NiO} / \mathrm{ZnO}$ heterojunction microflowers for the enhanced formaldehyde sensing properties. J. Alloy. Compd. 739, 260-269. doi: 10.1016/j.jallcom.2017.12.168

San, X. G., Wang, G. S., Liang, B., Ma, J., Meng, D., and Shen, Y. (2015). Flower-like $\mathrm{NiO}$ hierarchical microspheres self-assembled with nanosheets: surfactant-free solvothermal synthesis and their gas sensing properties. J. Alloy. Compd. 636, 357-362. doi: 10.1016/j.jallcom.2015.02.191

Singh, S., and Bandyopadhyay, M. (2010). Dissolved gas analysis technique for incipient fault diagnosis in power transformers: a bibliographic survey. IEEE Electr. Insul. Mag. 26, 41-46. doi: 10.1109/MEI.2010.5599978

Yu, Y., Xia, Y., Zeng, W., and Liu, R. (2017). Synthesis of multiple networked $\mathrm{NiO}$ nanostructures for enhanced gas sensing performance. Mater. Lett. 206, 80-83. doi: 10.1016/j.matlet.2017.06.119

Zhang, F. B., Zhou, Y. K., and Li, H. L. (2004). Nanocrystalline NiO as an electrode material for electrochemical capacitor. Mater. Chem. Phys. 83, 260-264. doi: 10.1016/j.matchemphys.2003.09.046

Zhang, L. X., Zhao, J. H., Lu, H. Q., Li, L., Zheng, J. F., Li, H., et al. (2012). Facile synthesis and ultrahigh ethanol response of hierarchically porous $\mathrm{ZnO}$ nanosheets. Sens. Actuators B Chem. 161, 209-215. doi: 10.1016/j.snb.2011.10.021

Zhang, Y., Zeng, W., Ye, H., and Li, Y. (2018). Enhanced carbon monoxide sensing properties of $\mathrm{TiO}_{2}$ with exposed $\{001\}$ facet: a combined first-principle and experimental study. Appl. Surf. Sci. 442, 507-516. doi: 10.1016/j.apsusc.2018.02.036

Zhu, L., Li, Y., and Zeng, W. (2018). Hydrothermal synthesis of hierarchical flowerlike $\mathrm{ZnO}$ nanostructure and its enhanced ethanol gas-sensing properties. Appl. Surf. Sci. 427, 281-287. doi: 10.1016/j.apsusc.2017.08.229

Zhu, L., Li, Y. Q., and Zeng, W. (2017). Enhanced ethanol sensing and mechanism of Cr-doped $\mathrm{ZnO}$ nanorods: experimental and computational study. Ceram. Int. 43, 14873-14879. doi: 10.1016/j.ceramint.2017.08.003

Zhu, L., and Zeng, W. (2017). Room-temperature gas sensing of $\mathrm{ZnO}$ based gas sensor: a review. Sens. Actuators A Phys. 267, 242-261. doi: 10.1016/j.sna.2017.10.021

Conflict of Interest Statement: The authors declare that the research was conducted in the absence of any commercial or financial relationships that could be construed as a potential conflict of interest.

Copyright (c) 2018 Zhang, Chen, Li, Jin, Cui and Song. This is an open-access article distributed under the terms of the Creative Commons Attribution License (CC BY). The use, distribution or reproduction in other forums is permitted, provided the original author(s) and the copyright owner(s) are credited and that the original publication in this journal is cited, in accordance with accepted academic practice. No use, distribution or reproduction is permitted which does not comply with these terms. 